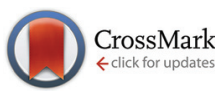

Cite this: Food Funct., 2016, 7, 3056

\section{Oligonol, a low-molecular-weight polyphenol derived from lychee fruit, protects the pancreas from apoptosis and proliferation via oxidative stress in streptozotocin-induced diabetic rats}

\author{
Chan Hum Park, ${ }^{a}$ Joo Young Lee, ${ }^{\mathrm{b}}$ Min Yeong Kim, ${ }^{\mathrm{b}}$ Sung Ho Shin, ${ }^{\mathrm{b}}$ \\ Seong-Soo Roh, ${ }^{b}$ Jae Sue Choi, ${ }^{c}$ Hae Young Chung, ${ }^{d}$ Yeong-Ok Song, ${ }^{e}$ \\ Yu Su Shin*a and Takako Yokozawa* ${ }^{\star}$
}

Received 22nd January 2016 Accepted 18th March 2016

DOI: $10.1039 / \mathrm{c} 6 f \circ 00088 \mathrm{f}$ www.rsc.org/foodfunction

\begin{abstract}
We have identified the effects of oligonol, a low-molecular polyphenol derived from lychee fruit, on diabetes-induced pancreatic damage via oxidative stress. Oligonol was orally administered at 10 or

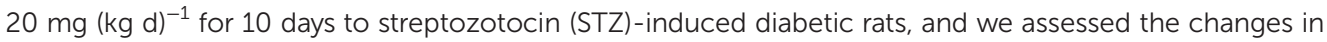
the serum glucose and insulin levels, as well as those of body weight and food and water consumption. In addition, analyses of the weight, insulin content, reactive oxygen species (ROS) level, and western blots of nicotinamide adenine dinucleotide phosphate (NADPH) oxidase-4 (Nox-4), p22 ${ }^{\text {phox }}$, p47 $7^{\text {phox }}$, phosphorc-Jun N-terminal kinase ( $\mathrm{p}$-JNK), Bax, cytochrome $c$, caspase 3, pancreatic-duodenal homeobox (PDX-1) and cyclin E were also performed in the pancreas. However, these unfavorable outcomes under diabetes were reversed by oligonol administration. Oligonol treatment led to significantly attenuated histological damage in the pancreas. In conclusion, this study suggests that oligonol protects the pancreas from Bax and PDX-1 via oxidative stress for the prevention or delaying of diabetes mellitus.
\end{abstract}

\section{Introduction}

The two main forms of diabetes are types 1 and $2 .{ }^{1}$ Both types are characterized by progressive $\beta$-cell failure. Type 1 diabetes is mediated by an autoimmune mechanism that results in reactive oxygen species (ROS) generation in an inflammatory process and is characterized by the destruction of pancreatic $\beta$-cells. ${ }^{2-4}$ The role of oxidative stress in the onset and progression of diabetes mellitus has been well-established. Therefore, diabetes represents an ideal candidate for studying the consequences of oxidative stress and its treatment.

\footnotetext{
${ }^{a}$ Department of Medicinal Crop Research, National Institute of Horticultural and Herbal Science, Rural Development Administration, Eumseong 369-873, Republic of Korea. E-mail: totoro69@korea.kr; Fax: +82-43-123-1234; Tel: +82-43-871-5584 ${ }^{b}$ College of Korean Medicine, Daegu Haany University, Gyeongsan 712-715, Republic of Korea

${ }^{c}$ Department of Food and Life Science, Pukyong National University, Busan 608-737, Republic of Korea

${ }^{d}$ Molecular Inflammation Research Center for Aging Intervention (MRCA), College of Pharmacy, Pusan National University, Busan 609-735, Republic of Korea ${ }^{e}$ Department of Food Science and Nutrition, Pusan National University, Busan 609-735, Republic of Korea

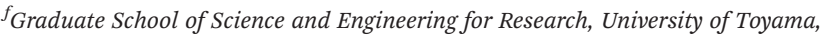
Toyama 930-8555, Japan. E-mail: yokozawa@inm.u-toyama.ac.jp;

Fax: +81-76-445-6549; Tel: +81-76-445-6667
}

Streptozotocin (STZ) is a nitrosourea analogue, preferentially taken up by pancreatic $\beta$-cells via the GLUT2 glucose transporter, and it causes DNA alkylation followed by the activation of poly-ADP ribosylation, leading to the depletion of the cytosolic concentration of $\mathrm{NAD}^{+}$and ATP. Enhanced ATP dephosphorylation after STZ treatment provides a substrate for xanthine oxidase, resulting in the formation of superoxide radicals. The NO moiety is liberated from STZ, leading to the destruction of $\beta$-cells by necrosis. ${ }^{5}$ Hence, an STZ-induced experimental diabetic animal model was chosen for the present study.

Natural extract products have recently attracted significant attention for the prevention and treatment of degenerative diseases. The lychee (Litchi chinensis, Sapindaceae), a subtropical fruit, is widely cultivated in Africa, Southeast Asia, China, Taiwan, Vietnam, and Japan. It is rich in polyphenols; Brat et $a .^{6}{ }^{6}$ reported that its polyphenol content per edible part is second only to strawberries. A particular feature of lychee polyphenols is a phenolic product containing catechin-type monomers and oligomers of proanthocyanidins. ${ }^{7}$ Proanthocyanidins are structurally characterized as polymers of catechin and have a high molecular weight. However, their absorption in the body is low when administered orally, and so their in vivo activity is not as high as expected. Moreover, proanthocyanidins with a high molecular weight are practically insoluble in 
water and have an astringent taste, binding to salivary proteins and mucous membranes in the mouth, ${ }^{8}$ and making them difficult to use in the food industry. Tanaka et al. ${ }^{9}$ were successful in converting high- into low-molecular-weight proanthocyanidin, which is utilizable in the food industry. These results support the capacity of oligonol to regulate the pathological conditions of chronic diseases, such as cancer, diabetes, cardiovascular diseases, and neurodegenerative disorders as well as age progression.

Recently, we reported supporting evidence for their preventive and/or therapeutic potential in diabetes-induced hepatic and renal injury. ${ }^{10-12}$ In this study, we explored the role of oligonol in ameliorating hyperglycemia-mediated oxidative damage to the pancreas in STZ-induced diabetic rats.

\section{Materials and methods}

\subsection{Oligonol}

Oligonol is produced by oligomerizing polyphenol polymers derived from lychee fruit. The safety of oligonol as a food or dietary supplement and as a pharmaceutical additive has been confirmed, as described previously. ${ }^{7}$ Oligonol comprises of a polyphenol mixture of $16.0 \%$ monomers (including catechin) and $13.9 \%$ dimers (including procyanidin and catechin), whereas lychee fruit polyphenol comprises of a mixture of $6.4 \%$ monomers and $9.8 \%$ dimers. Oligonol is commercially available (Amino Up Chemical).

\subsection{Chemicals and reagents}

Protease inhibitor mixture solution and 10\% neutral-buffered formalin were purchased from Wako Pure Chemical Industries, Ltd (Osaka, Japan). 2',7'-Dichlorofluorescein diacetate (DCFH-DA) was purchased from Molecular Probes (Eugene, OR, USA). The pure nitrocellulose membrane was purchased from Bio-Rad Laboratories (Tokyo, Japan). Phenylmethylsulfonyl fluoride (PMSF) was purchased from Sigma Chemical Co. (St Louis, MO, USA). Rabbit polyclonal antibodies against insulin, nicotinamide adenine dinucleotide phosphate (NADPH) oxidase (Nox)-4, p22 $2^{\text {phox }}, \mathrm{p} 47^{\text {phox }}$ and cyclin E, and mouse monoclonal antibodies against phosphor-c-Jun N-terminal kinase ( $\mathrm{p}$-JNK), Bax, cytochrome $c, \beta$-actin, and histone were purchased from Santa Cruz Biotechnology, Inc. (Santa Cruz, CA, USA). Rabbit polyclonal antibody against pancreaticduodenal homeobox 1 (PDX-1) (LifeSpan BioSciences, Seattle, WA, USA) and mouse monoclonal antibody against caspase 3 (BioVision, Mountain View, CA, USA) were also used. Goat anti-rabbit and goat anti-mouse IgG horseradish peroxidase (HRP)-conjugated secondary antibodies were purchased from Santa Cruz Biotechnology, Inc. ECL western blotting detection reagents were purchased from GE Healthcare (Piscataway, NJ, USA). All other chemicals and reagents were purchased from Sigma Chemical Co.

\subsection{Ethics statement}

The experimental animal care and treatment protocols complied with the Guide for the Care and Use of Laboratory Animals (National Academy of Sciences, NIH Publication 6-23, revised 1985) and were approved by the Ethics Committee for Research in Animals, Daegu Haany University (approval no. DHU-2013-036).

\subsection{Animals and treatment}

Six-week-old male Sprague-Dawley rats (180-200 g) were obtained from Daehan-Bio (Chungcheong, Korea). The room temperature and humidity were maintained automatically at about $25{ }^{\circ} \mathrm{C}$ and $55 \%$, respectively. All rats were allowed free access to laboratory pellet chow (CLEA Japan, Inc., Tokyo, Japan; comprising $24.0 \%$ protein, $3.5 \%$ lipids, and 60.5\% carbohydrates) and water. After several days of adaptation, the rats were injected intraperitoneally with $50 \mathrm{mg}$ per $\mathrm{kg}$ body weight STZ in $10 \mathrm{mM}$ citrate buffer at $\mathrm{pH}$ 4.5. The blood glucose level was determined and the body weight was measured 10 days after the injection, and to avoid any intergroup differences in these indices, the rats were divided into three experimental groups: group 1, diabetic rats received water $(n=5)$; groups 2 and 3 , diabetic rats received 10 or $20 \mathrm{mg}$ per $\mathrm{kg}$ body weight per day of oligonol $(n=5$, each) orally through gavage once a day, respectively. The administration dose and duration were determined based on other reports. ${ }^{10-12}$ The rats that underwent a sham injection of citrate buffer without STZ were also used as a non-diabetic group $(n=5)$. After 10 days of treatment, blood samples were obtained from the abdominal aorta under pentobarbital anesthesia (50 $\mathrm{mg} \mathrm{kg}^{-1}$, intraperitoneally), and serum was prepared by centrifugation. Subsequently, each rat was perfused with ice-cold physiological saline, and then the pancreas was harvested. The pancreas was divided into two parts. One part was placed in 10\% neutral buffered formalin for immunohistochemical analysis and the other one was snap-frozen in liquid nitrogen for ROS and western blot analyses.

\subsection{Measurement of glucose and insulin in the serum}

Serum glucose was determined using a commercial kit (Glucose CII-Test from Wako Pure Chemical Industries, Ltd, Osaka, Japan). The serum insulin (Morinaga Institute of Biological Science, Yokohama, Japan) level was estimated based on enzyme-linked immunosorbent assays.

\subsection{Determination of ROS generation in the pancreas}

ROS generation was measured employing the method of Ali et $a l .{ }^{13}$ Pancreatic tissues were homogenized on ice with $1 \mathrm{mM}$ EDTA-50 mM sodium phosphate buffer ( $\mathrm{pH}$ 7.4), and then $25 \mathrm{mM}$ DCFH-DA was added to the homogenates. After incubation for $30 \mathrm{~min}$, the changes in fluorescence values were determined at an excitation wavelength of $486 \mathrm{~nm}$ and an emission wavelength of $530 \mathrm{~nm}$. 
Table 1 Biochemical analyses

\begin{tabular}{|c|c|c|c|c|}
\hline Group & $\begin{array}{l}\text { Body weight change } \\
\text { (g per } 10 \text { days) }\end{array}$ & $\begin{array}{l}\text { Pancreas weight } \\
\text { (g per } 100 \mathrm{~g} \text { body weight) }\end{array}$ & $\begin{array}{l}\text { Food intake } \\
\text { (g per day) }\end{array}$ & $\begin{array}{l}\text { Water intake } \\
\text { (mL per day) }\end{array}$ \\
\hline Non-diabetic rats & $28.0 \pm 4.0^{*}$ & $0.43 \pm 0.03^{*}$ & $23.0 \pm 1.3^{*}$ & $27 \pm 1^{*}$ \\
\hline Vehicle-treated & $-24.9 \pm 3.5$ & $0.82 \pm 0.08$ & $36.8 \pm 2.3$ & $209 \pm 5$ \\
\hline Oligonol $10 \mathrm{mg}$ per $\mathrm{kg}$ body weight-treated & $-14.3 \pm 5.9$ & $0.76 \pm 0.05$ & $37.8 \pm 1.9$ & $212 \pm 5$ \\
\hline Oligonol $20 \mathrm{mg}$ per $\mathrm{kg}$ body weight-treated & $-17.8 \pm 5.4$ & $0.70 \pm 0.05$ & $40.2 \pm 2.8$ & $220 \pm 9$ \\
\hline
\end{tabular}

Data are expressed as mean \pm SEM. Significance: ${ }^{*} p<0.001$ vs. vehicle-treated diabetic rat values.

\subsection{Protein extraction and immunoblotting analyses}

Protein extraction was carried out according to the method of Yamabe et al. $^{14}$ Briefly, pancreatic tissue was homogenized with ice-cold lysis buffer, $\mathrm{pH} 7.5$, containing $137 \mathrm{mM} \mathrm{NaCl}$, $20 \mathrm{mM}$ Tris-HCl, 1\% Tween 20, 10\% glycerol, $1 \mathrm{mM}$ PMSF, and protease inhibitor mixture solution. Samples were then centrifuged at $3000 \mathrm{~g}$ for $10 \mathrm{~min}$ at $4{ }^{\circ} \mathrm{C}$. To ensure equal loading of the lanes, the protein concentration of each tissue was determined using a Pierce BCA protein assay kit (Thermo Scientific, Rockford, IL, USA) and then immunoblotting was carried out. For the determination of insulin, Nox-4, p $22^{\text {phox }}, \mathrm{p} 47^{\text {phox }}$, p-JNK, Bax, cytochrome $c$, caspase 3, PDX-1, cyclin E, and $\beta$-actin, each sample $(10 \mu \mathrm{g}$ of protein) was electrophoresed through $8-15 \%$ sodium dodecylsulfate polyacrylamide gel. The separated proteins were electrophoretically transferred to a nitrocellulose membrane, blocked with 5\% (w/v) skim milk solution for $1 \mathrm{~h}$, and then incubated with their corresponding primary anti-antibodies overnight at $4{ }^{\circ} \mathrm{C}$. After the blots were washed, they were incubated with goat anti-rabbit and/or goat anti-mouse IgG HRP-conjugated secondary antibodies for $90 \mathrm{~min}$ at room temperature. Each antigen-antibody complex was visualized using ECL western blotting detection reagents and detected by chemiluminescence with Sensi-Q2000 Chemidoc (Lugen Sci Co., Ltd, Seoul, Korea). Band densities were measured using ATTO Densitograph Software (ATTO Corporation, Tokyo, Japan) and quantified as the ratio to $\beta$-actin. The protein levels of the groups are expressed relative to those of non-diabetic rats (represented as 1).

\subsection{Histological examination}

The excised parts of pancreatic tissue were fixed immediately in $10 \%$ neutral-buffered formalin and embedded in paraffin. Paraffin sections were cut and stained with hematoxylin-eosin (HE) prior to optical microscopy examination. The sections were viewed and photographed using a Moticam Pro 205A microscope (Moticam Pro 205A, Moticam Instruments Inc., Richmond, Canada) with Motic Images Advanced 3.2 (Motic China Group Co. Ltd) software.

\subsection{Statistical analysis}

The data are expressed as means \pm SEM. Significance was assessed by one-way analysis of variance (ANOVA) followed by Dunnett's multiple comparison test (SPSS 11.5.1 for Windows,
2002, SPSS Inc., USA). Values of $p<0.05$ were considered significant.

\section{Results}

\subsection{Biochemical analyses}

During the 10 days of the experimental period, non-diabetic rats showed a significantly higher body weight gain than diabetic control rats, but the oral administration of 10 or $20 \mathrm{mg}$ per $\mathrm{kg}$ oligonol did not affect body weight changes in diabetic rats. The pancreatic weight in the diabetic control rats was 1.91 times higher than that in the non-diabetic rats, but was reduced slightly in the rats administered oligonol at an oral dose of $20 \mathrm{mg} \mathrm{kg}{ }^{-1}$. The diabetic control rats showed an increased food and water intake compared with non-diabetic rats. There was, however, no significant reduction in these parameters on the administration of oligonol, as shown in Table 1.

\subsection{Serum glucose and insulin levels}

As shown in Table 2, diabetic control rats maintained a level of about $410 \mathrm{mg} \mathrm{dL}{ }^{-1}$, while non-diabetic rats showed a level of around $130 \mathrm{mg} \mathrm{dL}{ }^{-1}$; however, oligonol-administered groups showed a decrease in this level dose-dependently. On the other hand, diabetic control rats showed a marked decrease in the serum insulin level, but the oral administration of oligonol at 10 or $20 \mathrm{mg} \mathrm{kg}^{-1}$ suppressed this decrease.

\subsection{Insulin content in the pancreas}

The insulin content of diabetic control rats decreased to $15 \%$ of that of the non-diabetic rats, but oligonol administration

Table 2 Serum glucose and insulin levels

\begin{tabular}{lll}
\hline Group & $\begin{array}{l}\text { Glucose } \\
\left(\mathrm{mg} \mathrm{dL}^{-1}\right)\end{array}$ & $\begin{array}{l}\text { Insulin } \\
\left(\mathrm{ng} \mathrm{mL} \mathrm{m}^{-1}\right)\end{array}$ \\
\hline $\begin{array}{l}\text { Non-diabetic rats } \\
\begin{array}{l}\text { Diabetic rats } \\
\quad \text { Vehicle-treated }\end{array}\end{array}$ & $129 \pm 1^{* *}$ & $3.06 \pm 0.38^{* *}$ \\
$\quad \begin{array}{ll}\text { Oligonol 10 mg per kg body weight-treated } \\
\text { Oligonol 20 mg per kg body weight-treated }\end{array}$ & $392 \pm 5^{*}$ & $0.31 \pm 0.01$ \\
$\quad 372 \pm 3^{* *}$ & $0.36 \pm 0.01^{* *}$
\end{tabular}

Data are expressed as mean \pm SEM. Significance: ${ }^{*} p<0.05,{ }^{*} p<0.001$ $v s$. vehicle-treated diabetic rat values. 

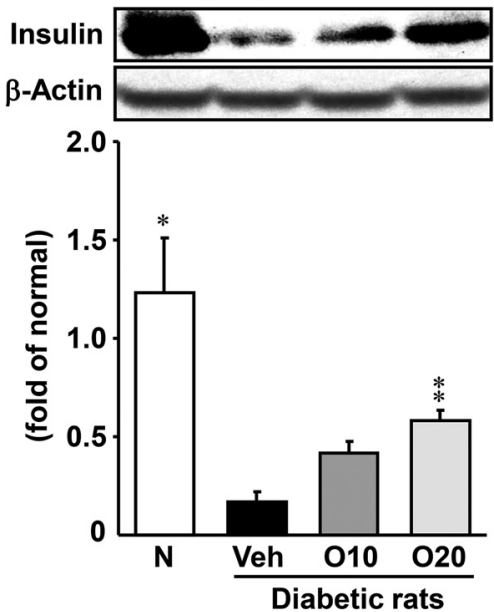

Fig. 1 Western blot analysis of the protein immunocontent in insulin in the pancreatic tissue of STZ-treated diabetic rats. Values are expressed as the mean \pm SEM of $5-8$ rats per experimental group. ${ }^{*} p<0.01,{ }^{* *} p<$ 0.01 vs. vehicle-treated diabetic rats.

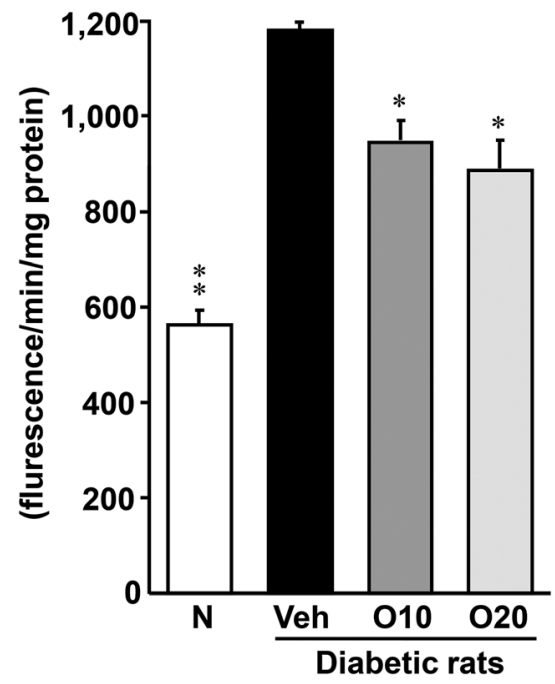

Fig. 2 Effects of oligonol on the levels of ROS in the pancreatic tissue of STZ-treated diabetic rats. Values are expressed as the mean \pm SEM of $5-8$ rats per experimental group. ${ }^{*} p<0.01,{ }^{* *} p<0.01$ vs. vehicle-treated diabetic rats.

ameliorated the level dose-dependently, and the $20 \mathrm{mg}$ per $\mathrm{kg}$ oligonol-treated group showed a significant increase (Fig. 1).

\subsection{ROS level in the pancreas}

As shown in Fig. 2, the diabetic control rats had a significantly higher level of ROS in the pancreas than the non-diabetic rats. This elevation was significantly attenuated by the administration of 10 or $20 \mathrm{mg}$ per $\mathrm{kg}$ oligonol.

3.5. Nox-4, $\mathrm{p}^{22^{\text {phox }}}$, and $\mathrm{p} 47^{\text {phox }}$ protein expressions in the pancreas

The protein expressions of NADPH oxidase subunits (except $\left.\mathrm{p} 47^{\text {phox }}\right)$ were significantly elevated in diabetic control rats compared with non-diabetic rats, as shown in Fig. 3. However, the oligonol-treated groups showed a reduction in expressions, and there was a significant decrease in Nox-4 and p22 $2^{\text {phox }}$ expressions in rats treated with $20 \mathrm{mg}$ per kg oligonol (Fig. 3A and B). In addition, oligonol administration markedly reduced p $47^{\text {phox }}$ expression in a dose-dependent manner (Fig. 3C).

\section{6. $\quad$ p-JNK protein expression in the pancreas}

The expression level of the p-JNK protein was enhanced in the pancreas of diabetic control rats, as compared to the nondiabetic rats (Fig. 4). The oral administration of $20 \mathrm{mg}$ per $\mathrm{kg}$ oligonol to diabetic rats significantly decreased this enhanced expression of p-JNK.

\subsection{Apoptosis-related protein expressions in the pancreas}

As shown in Fig. 5, the expression of apoptosis-related proteins such as Bax, cytochrome $c$, and caspase 3 was significantly higher in the diabetic control rats, as compared to nondiabetic rats. The increased apoptotic protein expressions were decreased significantly in the diabetic rats treated with $20 \mathrm{mg}$ per kg oligonol.

\subsection{Proliferation-related protein expressions in the pancreas}

The protein expressions of PDX-1 and cyclin E were significantly lower in the diabetic control compared with nondiabetic rats. The oligonol-treated group showed a significant up-regulation of PDX-1 (Fig. 6A) but not cyclin E compared with diabetic control rats (Fig. 6B).

\subsection{Histology}

Fig. 7 shows the results of histological examination using HE staining, which detects pancreatic cell damage. The level of cellular damage, such as necrotic changes, karyolysis and severe reduction of $\beta$-cells, was higher in the pancreas of diabetic control rats than in those of non-diabetic rats. However, these histological studies demonstrated that the administration of oligonol had a significant protective effect against these lesions.

\section{Discussion}

The pancreas is a complex of exocrine and endocrine glands that controls many homeostatic functions. In the development of type 1 diabetes, chronic hyperglycemia can exert deleterious effects on $\beta$-cell function, ${ }^{15,16}$ and the mechanisms of glucotoxicity involve several transcriptional factors and are, at least in part, mediated by the generation of chronic oxidative stress. ${ }^{17,18} \beta$-Cell dysfunction caused by glucotoxicity has been reported to be potentially reversible with the restoration of metabolic control. ${ }^{19}$ Therefore, an effective remedy to attenuate the decline in pancreatic function by suppressing oxidative stress with the restoration of glucose metabolism may help to prevent the development of diabetic complications, while attempts to stimulate insulin secretion and improve insulin 
(A)
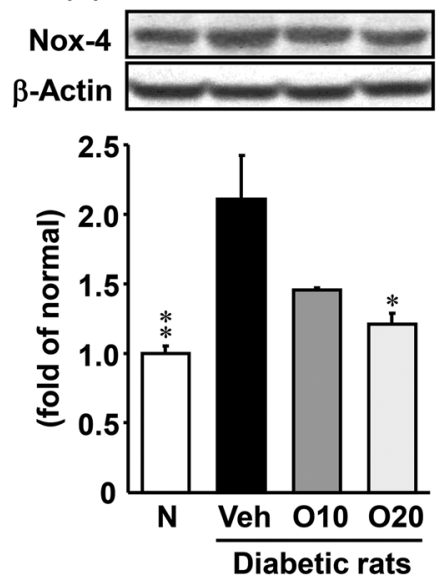

(B)
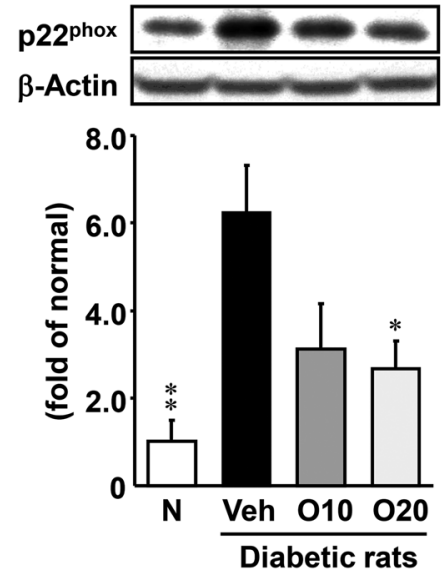

(C)
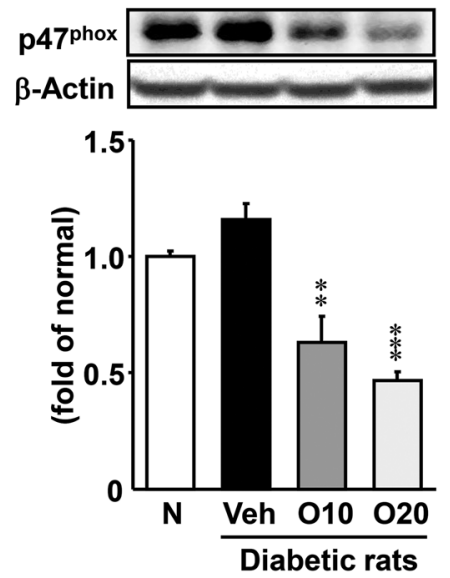

Fig. 3 Western blot analysis of the protein immunocontent in association with the NADPH oxidase subunit in the pancreatic tissue of STZ-treated diabetic rats. (A) Nox-4; (B) p22 ${ }^{\text {phox; }}$ (C) $p 47^{\text {phox }}$. Values are expressed as the mean \pm SEM of $5-8$ rats per experimental group. ${ }^{*} p<0.05,{ }^{* *} p<0.01$, ${ }^{* * *} p<0.001$ vs. vehicle-treated diabetic rats.

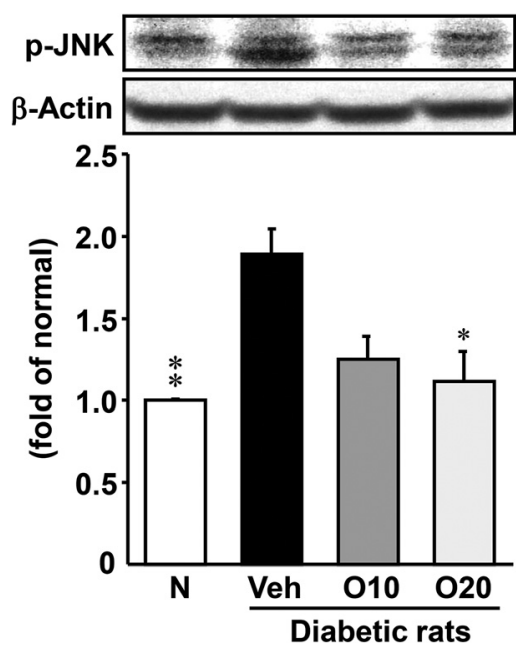

Fig. 4 Western blot analysis of the protein immunocontent in association with oxidative stress in the pancreatic tissue of STZ-treated diabetic rats. Values are expressed as the mean \pm SEM of $5-8$ rats per experimental group. ${ }^{*} p<0.01,{ }^{* *} p<0.001$ vs. vehicle-treated diabetic rats.

action with drug therapies are temporarily helpful but, in fact, are ultimately unable to prevent progressive $\beta$-cell dysfunction.

Phenolic compounds are phytochemicals widely distributed in the human diet through the intake of plant-derived products that are abundant in fruit, vegetables, cereals, cocoa derivatives, and nuts, as well as in beverages such as tea, coffee, soy milk, and red wine..$^{20-22}$ These phenolic compounds are the most beneficial antioxidants in the human diet. ${ }^{23}$ Many studies have discovered that the intake of natural antioxidants is correlated with a low occurrence of cancer, heart disease, diabetes, and age-related diseases, but there are still controversial opinions. ${ }^{24-26}$ Oligonol is a new dietary phenolic product derived from lychee fruit polyphenols containing cate- chin-type monomers and low-molecular-weight oligomers. ${ }^{7}$ In recent studies, accumulating evidence has demonstrated that oligonol can exert its physiological and biochemical effects, such as anticancer, antioxidant, anti-inflammation, and antiobesity effects, in vitro and in vivo. ${ }^{7,27-29}$ However, the effects of oligonol on apoptosis and proliferation linked to oxidative stress damage and the development of pancreatic disorders have not been investigated. In this study, we assessed the protective effects of oligonol against diabetes by investigating pinpointing markers in the serum and pancreas of STZ-induced diabetic rats, thereby highlighting oligonol as a promising anti-diabetic agent for type 1 diabetes.

The destruction of $\beta$-cells and disorder of insulin secretion in the diabetic state cause physico-metabolic abnormalities such as a decrease in body weight gain and an increase in the pancreatic weight, food intake, and water intake. The STZinduced diabetic rats in this study also showed these changes. However, the administration of oligonol slightly, not significantly, decreased these diabetes-induced physiological changes, but led to a decrease in the pancreatic weight.

A number of mechanisms contribute to the development of pancreatic disorders, that is, glucotoxicity, oxidative stress, advanced glycation end-product accumulation, fibrogenesis, and cytokine production. ${ }^{30}$ Recently, several sources have been emphasized as being major contributors to ROS production. ROS play an important role in insulin resistance and pancreatic $\beta$-cell dysfunction, a highly prevalent condition implicated in the development of diabetes. ${ }^{31-33}$ Under diabetic conditions, hyperglycemia may induce large amounts of ROS that are responsible for the progressive dysfunction of $\beta$-cells, worsening insulin resistance and further promoting relative insulin deficiency. ${ }^{34} \beta$-Cells, in particular, are very sensitive to ROS because they are low in free radical quenching (antioxidant) enzymes. ${ }^{35}$ The ROS formed may also indirectly damage cells by activating a variety of stress-sensitive intracellular signaling pathways, including nuclear factor- $\mathrm{\kappa B}$ and 
(A)
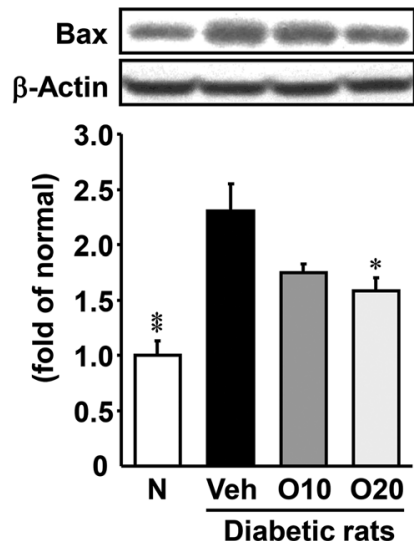

(B)
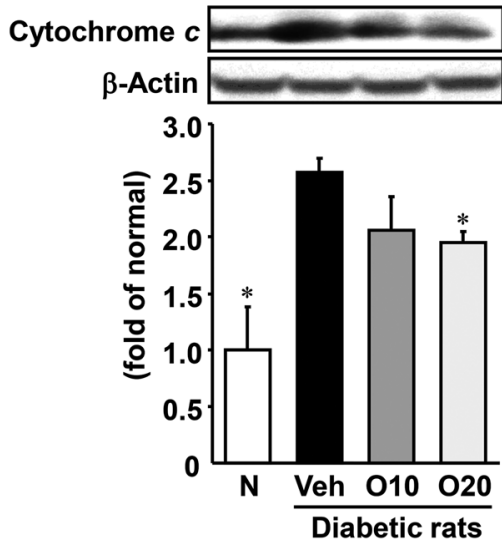

(C)

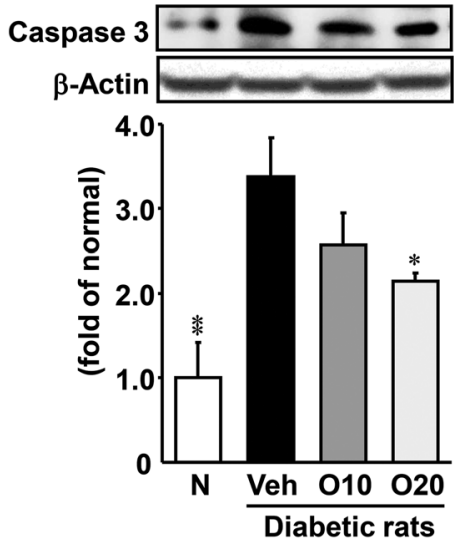

Fig. 5 Western blot analysis of the protein immunocontent in association with apoptosis in the pancreatic tissue of STZ-treated diabetic rats. (A) Bax; (B) cytochrome $c$; (C) caspase 3. Values are expressed as the mean \pm SEM of 5-8 rats per experimental group. ${ }^{*} p<0.05$, ${ }^{* *} p<0.01$ vs. vehicletreated diabetic rats.

mitogen-activated protein kinase. In the present study, oligonol administration suppressed pancreatic ROS, and also NADPH oxidase subunits and p-JNK as oxidative stress-related proteins.

JNK is involved not only in the inhibition of insulin secretion but also in the loss of pancreatic $\beta$-cells induced by proinflammatory stimuli. ${ }^{36,37} \mathrm{JNK}$ also participates in pancreatic $\beta$-cell death. Apoptosis, the main cause of $\beta$-cell death at the onset of type 1 diabetes, is a highly regulated process, activated and/or modified by extracellular signals, intracellular ATP levels, phosphorylation cascades, and the expression of pro- and anti-apoptotic genes. ${ }^{38}$ It has been accepted that apoptosis plays an important role in different types of environmental stimulator-induced cell deaths. In mammalian cells, there are two major apoptotic pathways: the death-receptor pathway (extrinsic death pathways) and mitochondrial pathway (intrinsic pathways). ${ }^{39}$ The intrinsic death pathway involves the mitochondrial release of apoptotic proteins, such as p53, Bcl-2, Bax, and cytochrome $c{ }^{40-43}$ Apoptotic protein caspase 3 is the key effector and could be activated through mitochondria-dependent Fas/FasL-mediated pathways. In this study, the administration of oligonol to diabetic rats significantly suppressed protein expressions of Bax, cytochrome $c$, and caspase 3 , indicating that oligonol protected against mitochondrial dysfunction through the suppression of apoptotic proteins in pancreatic tissue.

PDX-1 is a homeodomain-containing transcription factor that plays a pivotal role in the development and differentiation of the pancreas. This transcription factor is predominantly expressed in $\beta$-cells of the islets, where it directly or indirectly regulates the expression of insulin transcription through the formation of a complex with transcriptional coactivators on the proximal insulin promoter ${ }^{44,45}$ Moreover, cyclin $\mathrm{E}$ is a member of the cyclin family. Cyclin $E$ binds to $G_{1}$ phase Cdk2, which is required for the transition from the $G_{1}$ to $S$ phase of the cell cycle that determines cell division. ${ }^{46}$ Because of the well-documented importance of PDX-1 and cyclin E in mediat-
(A)
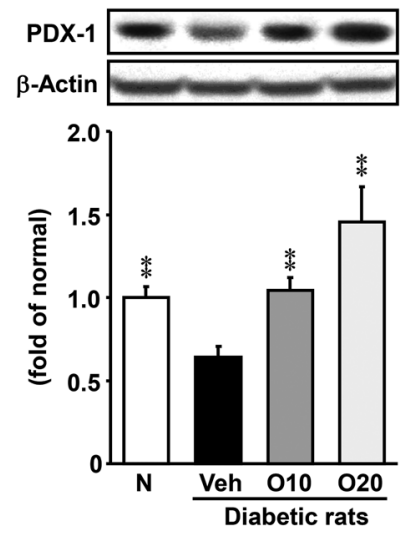

(B)
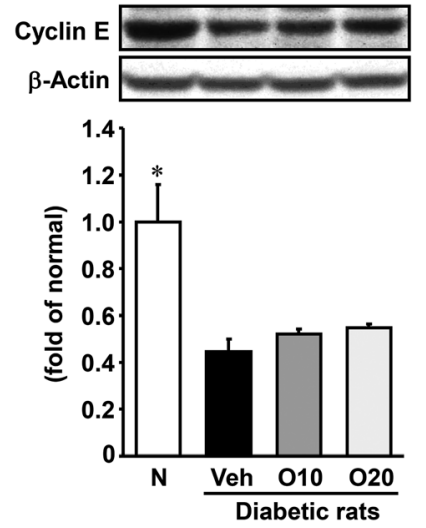

Fig. 6 Western blot analysis of the protein immunocontent in association with proliferation in the pancreatic tissue of STZ-treated diabetic rats. (A) PDX-1; (B) cyclin E. Values are expressed as the mean \pm SEM of $5-8$ rats per experimental group. ${ }^{*} p<0.05,{ }^{* *} p<0.01$ vs. vehicletreated diabetic rats.

ing cellular proliferation, we performed western blot analyses of the proliferation-related protein expression in pancreatic tissue. In this study, STZ-induced diabetic rats showed downregulated protein expressions of PDX-1 and cyclin E. In contrast, the oral administration of oligonol significantly increased the level of the PDX-1 protein, whereas the cyclin E protein level showed a slight change with oligonol. These results indicated that the administration of oligonol effectively ameliorated pancreatic proliferation and insulin gene expression in diabetic rats by modulating the PDX-1 (Fig. 8).

In conclusion, diabetic rats showed increased pancreatic damage associated with the expression of JNK pathway-derived apoptotic genes (Bax, cytochrome $c$, and caspase 3 ) and cellular proliferation-related transcription factor (PDX-1). However, 

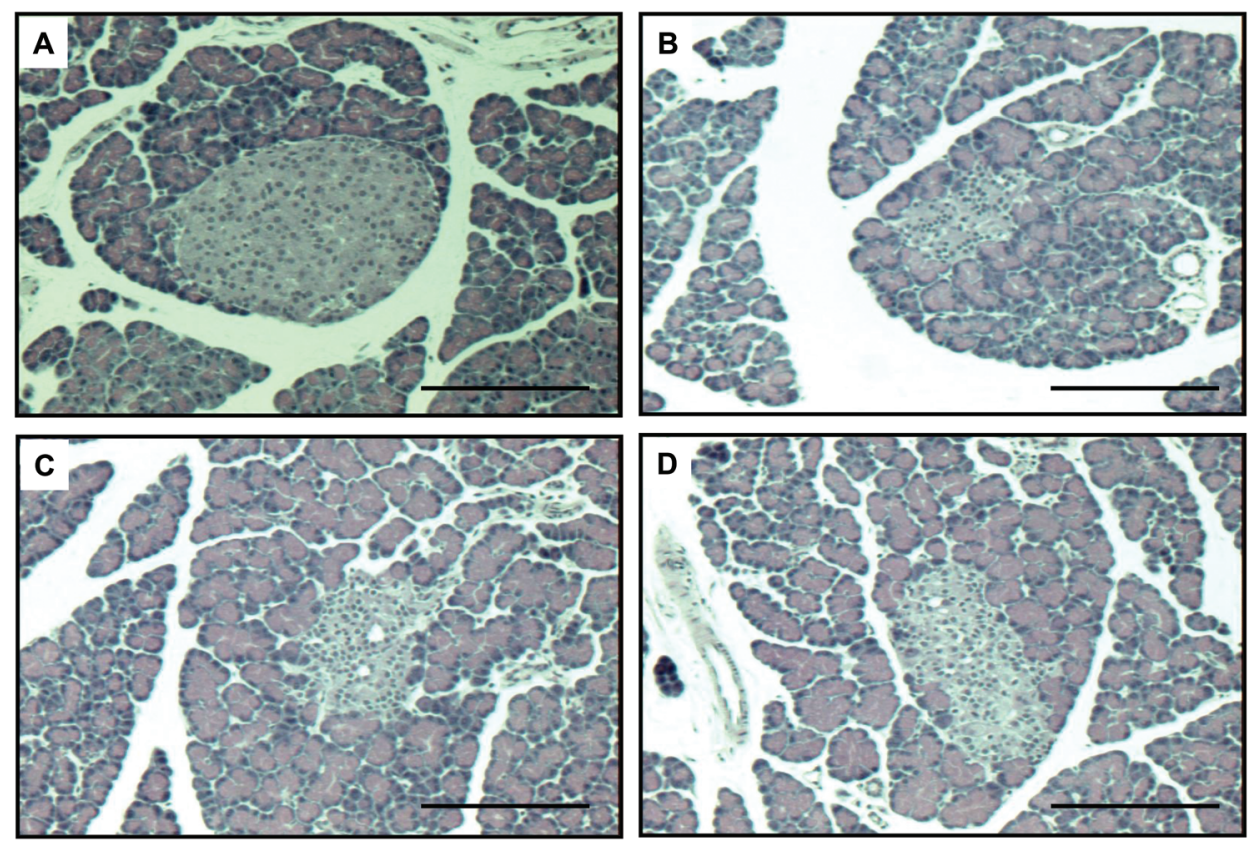

Fig. $7 \mathrm{HE}$ staining of pancreatic tissues. Original magnification $\times 200$. (A) non-diabetic rats; (B) vehicle-treated diabetic rats; (C) $10 \mathrm{mg}$ per kg oligonol-treated diabetic rats; (D) $20 \mathrm{mg}$ per kg oligonol-treated diabetic rats. Scale bar is $100 \mu \mathrm{m}$.

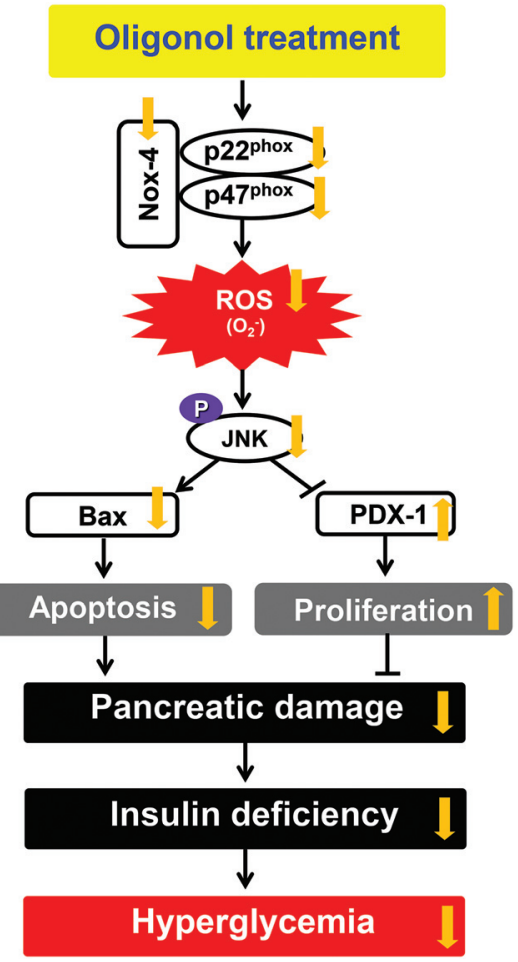

Fig. 8 Predicted mechanism in pancreatic tissue on administering oligonol against diabetes-induced apoptosis and proliferation inhibition.

these unfavorable outcomes were reversed by oligonol administration to diabetic rats. The oligonol treatment of diabetic rats led to significant attenuations of hyperglycemia, insulin levels in the serum and pancreas, and histological damage of the pancreas. We, therefore, believe that oligonol is a promising dietary supplement for the prevention or delaying of diabetes mellitus.

\section{Abbreviations}

$\begin{array}{ll}\text { DCFH-DA } & 2^{\prime}, 7^{\prime} \text {-Dichlorofluorescein diacetate } \\ \text { DTT } & \text { Dithiothreitol } \\ \text { HE } & \text { Hematoxylin-eosin } \\ \text { HRP } & \text { Horseradish peroxidase } \\ \text { NADPH } & \text { Nicotinamide adenine dinucleotide phosphate } \\ \text { Nox } & \text { NADPH oxidase } \\ \text { PDX-1 } & \text { Pancreatic-duodenal homeobox 1 } \\ \text { p-JNK } & \text { Phosphor-c-Jun N-terminal kinase } \\ \text { PMSF } & \text { Phenylmethylsulfonyl fluoride } \\ \text { ROS } & \text { Reactive oxygen species } \\ \text { SDS-PAGE } & \text { Sodium dodecylsulfate polyacrylamide gel } \\ \text { STZ } & \text { Streptozotocin }\end{array}$

\section{Conflict of interest}

The authors declare that there are no conflicts of interest.

\section{Acknowledgements}

This work was supported by grants from Rural Development Administration (Cooperative Research Program for Agriculture Science \& Technology Development, Project no. PJ011869012016), Republic of Korea. 


\section{References}

1 The Expert Committee on the Diagnosis and Classification of Diabetes Mellitus, Diabetes Care, 1997, 20, 1183-1197.

2 G. Kwon, J. A. Corbett, C. P. Rodi, P. Sullivan and M. L. McDaniel, Endocrinology, 1995, 136, 4790-4795.

3 T. Mandrup-Poulsen, Diabetologia, 1996, 39, 1005-1029.

4 A. Rabinovitch and W. L. Suarez-Pinzon, Biochem. Pharmacol., 1998, 55, 1139-1149.

5 T. Szkudelski, Physiol. Res., 2001, 50, 536-546.

6 P. Brat, S. Georgé, A. Bellamy, L. Du Chaffaut, A. Scalbert, L. Mennen, N. Arnault and M. J. Amiot, J. Nutr., 2006, 136, 2368-2373.

7 H. Fujii, H. Nishioka, K. Wakame, B. A. Magnuson and A. Roberts, Food Chem. Toxicol., 2008, 46, 3553-3562.

8 E. Haslam, J. Nat. Prod., 1996, 59, 205-215.

9 T. Tanaka, N. Yoshitake, P. Zhao, Y. Matsuo, I. Kouno and G. Nonaka, Jpn. J. Food Chem., 2007, 14, 134-139.

10 J. S. Noh, H. Y. Kim, C. H. Park, H. Fujii and T. Yokozawa, Br. J. Nutr., 2010, 104, 1120-1128.

11 J. S. Noh, C. H. Park and T. Yokozawa, Br. J. Nutr., 2011, 106, 1013-1022.

12 C. H. Park, T. Yokozawa and J. S. Noh, J. Nutr., 2014, 144, 1150-1157.

13 S. F. Ali, C. P. LeBel and S. C. Bondy, Neurotoxicology, 1992, 13, 637-648.

14 N. Yamabe, T. Yokozawa, T. Oya and M. Kim, J. Pharmacol. Exp. Ther., 2006, 319, 228-236.

15 A. Moran, H. J. Zhang, L. K. Olson, J. S. Harmon, V. Poitout and R. P. Robertson, J. Clin. Invest., 1997, 99, 534-539.

16 C. E. Gleason, M. Gonzalez, J. S. Harmon and R. P. Robertson, Am. J. Physiol.: Endocrinol. Metab., 2000, 279, E997-1002.

17 H. Kaneto, G. Xu, K. H. Song, K. Suzuma, S. Bonner-Weir, A. Sharma and G. C. Weir, J. Biol. Chem., 2001, 276, 3109931104.

18 D. R. Laybutt, H. Kaneto, W. Hasenkamp, S. Grey, J. C. Jonas, D. C. Sgroi, A. Groff, C. Ferran, S. Bonner-Weir, A. Sharma and G. C. Weir, Diabetes, 2002, 51, 413-423.

19 D. LeRoith, Am. J. Med., 2002, 113(Suppl 6A), 3S-11S.

20 C. Manach, A. Scalbert, C. Morand, C. Rémésy and L. Jiménez, Am. J. Clin. Nutr., 2004, 79, 727-747.

21 A. Crozier, T. Yokota, I. B. Jaganath, S. C. Marks, M. Saltmarsh and M. N. Clifford, in Plant Secondary Metabolites: Occurrence, Structure and Role in the Human Diet, ed. A. Crozier, M. N. Clifford and H. Ashihara, Blackwell Publishing, Oxford, 2006, pp. 208-302.

22 S. Torabian, E. Haddad, S. Rajaram, J. Banta and J. Sabaté, J. Hum. Nutr. Diet., 2009, 22, 64-71.

23 A. Scalbert, I. T. Johnson and M. Saltmarsh, Am. J. Clin. Nutr., 2005, 81(suppl), 215S-217S.

24 M. G. L. Hertog, D. Kromhout, C. Aravanis, H. Blackburn, R. Buzina, F. Fidanza, S. Giampaoli, A. Jansen, A. Menotti, S. Nedeljkovic, M. Pekkarinen, B. S. Simic, H. Toshima,
E. J. M. Feskens, P. C. H. Hollman and M. B. Katan, Arch. Intern. Med., 1995, 155, 381-386.

25 J. W. Mclarty, in Antioxidants and Disease Prevention, ed. H. S. Garewal, CRC Press, New York, 1997, pp. 45-66.

26 D. Albanes and T. J. Hartman, in Antioxidant Status, Diet, Nutrition and Health, ed. A. M. Papas, CRC Press, Florida, 1999, pp. 497-544.

27 E. H. Jo, S. J. Lee, N. S. Ahn, J. S. Park, J. W. Hwang, S. H. Kim, O. I. Aruoma, Y. S. Lee and K. S. Kang, Eur. J. Cancer Prev., 2007, 16, 342-347.

28 J. K. Kundu, E. J. Chang, H. Fujii, B. Sun and Y. J. Surh, Photochem. Photobiol., 2008, 84, 399-406.

29 J. Ogasawara, K. Kitadate, H. Nishioka, H. Fujii, T. Sakurai, T. Kizaki, T. Izawa, H. Ishida and H. Ohno, Phytother. Res., 2011, 25, 467-471.

30 C. Tikellis, M. E. Cooper and M. C. Thomas, Int. J. Biochem. Cell Biol., 2006, 38, 737-751.

31 J. L. Evans, I. D. Goldfine, B. A. Maddux and G. M. Grodsky, Diabetes, 2003, 52, 1-8.

32 J. L. Evans, B. A. Maddux and I. D. Goldfine, Antioxid. Redox Signaling, 2005, 7, 1040-1052.

33 N. Houstis, E. D. Rosen and E. S. Lander, Nature, 2006, 440, 944-948.

34 R. P. Robertson, J. Harmon, P. O. Tran, Y. Tanaka and H. Takahashi, Diabetes, 2003, 52, 581-587.

35 J. L. Evans, Indian J. Med. Res., 2007, 125, 355-372.

36 A. Ammendrup, A. Maillard, K. Nielsen, N. Aabenhus Andersen, P. Serup, O. Dragsbaek Madsen, T. MandrupPoulsen and C. Bonny, Diabetes, 2000, 49, 1468-1476.

37 W. H. Kim, J. W. Lee, B. Gao and M. H. Jung, Cell. Signalling, 2005, 17, 1516-1532.

38 D. L. Eizirik and T. Mandrup-Poulsen, Diabetologia, 2001, 44, 2115-2133.

39 D. Jin, D. M. Ojcius, D. Sun, H. Dong, Y. Luo, Y. Mao and J. Yan, Infect. Immun., 2009, 77, 799-809.

40 Z. He, W. Y. Ma, T. Hashimoto, A. M. Bode, C. S. Yang and Z. Dong, Cancer Res., 2003, 63, 4396-4401.

41 X. Zhang, R. Vallabhaneni, P. A. Loughran, R. Shapiro, X. M. Yin, Y. Yuan and T. R. Billiar, Apoptosis, 2008, 13, 983-992.

42 M. Chaudhari, R. Jayaraj, A. S. Bhaskar and P. V. Lakshmana Rao, Toxicology, 2009, 262, 153-161.

43 J. Ravindran, N. Gupta, M. Agrawal and A. S. Bala Bhaskar, Apoptosis, 2011, 16, 145-161.

44 H. Watada, Y. Kajimoto, J. Miyagawa, T. Hanafusa, K. Hamaguchi, T. Matsuoka, K. Yamamoto, Y. Matsuzawa, R. Kawamori and Y. Yamasaki, Diabetes, 1996, 45, 18261831.

45 T. Iype, J. Francis, J. C. Garmey, J. C. Schisler, R. Nesher, G. C. Weir, T. C. Becker, C. B. Newgard, S. C. Griffen and R. G. Mirmira, J. Biol. Chem., 2005, 280, 16798-16807.

46 P. W. Hinds, S. Mittnacht, V. Dulic, A. Arnold, S. I. Reed and R. A. Weinberg, Cell, 1992, 70, 993-1006. 